\title{
Behavioral Economics Optimized Renewable Power Grid: A Case Study of Household Energy Storage ${ }^{\dagger}$
}

\author{
Shengyu Tao ${ }^{1,2,3}$, Yiqiang Zhang ${ }^{1,2}$, Meng Yuan ${ }^{1,2}$, Ruixiang Zhang ${ }^{1,2}$, Zhongyan Xu ${ }^{1,2}$ and Yaojie Sun ${ }^{1,2,3, *}$ \\ 1 Department of Light Sources and Illuminating Engineering, Fudan University, Shanghai 200438, China; \\ 19210720062@fudan.edu.cn (S.T.); 18210720067@fudan.edu.cn (Y.Z.); 20110720027@fudan.edu.cn (M.Y.); \\ 20210720020@fudan.edu.cn (R.Z.); $19210860051 @ f u d a n . e d u . c n(Z . X$. \\ 2 Shanghai Engineering Research Center for Artificial Intelligence and Integrated Energy System, Fudan \\ University, Shanghai 200433, China \\ 3 Institute for Six-Sector Economy, Fudan University, Shanghai 200433, China \\ * Correspondence: yjsun@fudan.edu.cn; Tel.: +86-021-55665508 \\ + This paper is an extended version of our paper published in 2021 IEEE 4th International Conference on \\ Electronics Technology (ICET), Chengdu, China, 7-10 May 2021; pp. 383-388.
}

Citation: Tao, S.; Zhang, Y.; Yuan, M.; Zhang, R.; Xu, Z.; Sun, Y. Behavioral Economics Optimized Renewable Power Grid: A Case Study of Household Energy Storage . Energies 2021, 14, 4154. https://doi.org/ $10.3390 /$ en14144154

Academic Editor: David Borge-Diez

Received: 16 June 2021

Accepted: 8 July 2021

Published: 9 July 2021

Publisher's Note: MDPI stays neutral with regard to jurisdictional claims in published maps and institutional affiliations.

Copyright: (c) 2021 by the authors. Licensee MDPI, Basel, Switzerland. This article is an open access article distributed under the terms and conditions of the Creative Commons Attribution (CC BY) license (https:// creativecommons.org/licenses/by/ $4.0 /)$.
Abstract: Power systems optimization is generally subject to the compromise between performance and cost. The 2021 Texas grid outage illustrates the worldwide dangers for the regional-centralized power grid, with comparable advantages to safety and flexibility for the distributed energy system. The storage of household batteries helps balance grid load and increase system stability and flexibility. However, household storage battery is still not widely used today because of its high costs. Currently, research on increasing household battery storage applicability is focused largely on optimizing economic strategies, such as configuration, dispatching and subsidy policies, which rely substantially more on technologies and financial perspectives. Consumers are not 'rational' individuals, and non-economic incentives can affect their decisions without raising prices. This paper consequently proposes to encourage users to acquire household battery storage to increase efficiency of power dispatching and economic advantages based on behavioral economics. In this paper, an empirical research builds upon the utility model of behavioral economics incentives and purchase willingness. Moreover, the multi-objective genetic algorithm is utilized to optimize the dispatching of household battery storage by using grid variance and user revenues as optimizing goals. The results of this paper show that the behavioral economics incentive improves intention to buy the household battery energy storage by $10.7 \%$ without raising subsidies. By improving the energy dispatching strategy, peak-load shifting performance and user revenues are improved by $4.2 \%$ and $10.6 \%$, respectively.

Keywords: household energy storage; behavioral economics; multi-objective optimization; energy dispatching strategy

\section{Introduction}

The optimization of the energy system typically faces a balance between higher efficiency and reduced expenses. In attaining grid efficiency, household battery storage is of major importance for improving renewable power absorbance and for improving the grid stability of regional electricity dispatching [1]. However, due to the high cost, the global usage is not high enough, especially in the countries with relatively low energy prices However, because of the high cost, global use of the household battery storage is not adequate, particularly in the countries where energy prices are relatively low $[2,3]$. Furthermore, the recent grid blackout in Texas (February 2021) indicates it is unreliable to only depend on the centralized regional grid. The distributed energy structure offers relative safety and flexibility advantages [4]. In this context, the power system reliability is hopeful to be guaranteed by promoting the penetration of household battery energy storage $[5,6]$. 
So far, existing researches such as power system configuration, economic benefits optimization, energy dispatching strategies and subsidy policies, have been adopted to enhance the applicability of household battery energy storage, which are currently technologically and financially dependent $[7,8]$. For instance, Alejandro et al. conducted an economic optimization on self-consumption and load transfer with dynamic tariffs applied in a photovoltaic system. The results demonstrated that if the battery is utilized for a photovoltaic system with self-consumption considered under a single set price, the maximum monetary value of installed power per kilowatt-hour can be achieved [9]. Kanzumba developed an optimum model for energy management for two interactive prosumers in peer-to-peer energy sharing to provide loads from both hybrid renewable sources and energy storage systems, while reducing energy costs bought from the state grid [10]. Zhang et al. also simulated and analyzed a grid-tied photovoltaic system with battery energy storage system under different electricity prices and configurations from both a technical and an economic perspective. It is found that the system with high selfsufficiency is more vulnerable to the subsidy policy compared to the high self-consumption system [11]. Schopfera et al. created a technologically and economically combined model for the photovoltaic with energy storage to optimize the system configuration under a specific load profile [12]. Andreas and Christoph also found that the economic incentives for initial battery investment would be a dominating factor for photovoltaic systems from the user perspective [13]. Valentin et al. compared the influence on the investment of photovoltaic energy storage systems under different subsidy and geographical variations. Germany benefits from the photovoltaic energy storage system, while such a system in Ireland is not yet profitable. This position might soon change, though, given the drop in technological prices. In addition, in conjunction with economic incentives the photovoltaic storage system can reduce the grid demand to 25 to $35 \%$ [14].

Current researches, to a certain degree, improved the applicability of household battery energy storage systems, but are based largely on technology advances and financial supports without taking account of behavior psychology. Behavioral economics found the decisions and cognition of individuals to be biased and to psychologically impact decisionmaking. Behavioral economics shows that persons have a time discount, loss aversion, status quo bias and compliance which are extremely important in real-world instances [15]. Richard Thaler, Nobel Prize winner, has pushed his policies towards the usage of household power. He observed that consumers lowered $40 \%$ of their electricity use by putting red light alerts to help them save energy at the peak period [16]. The irrational decision making of the intuitive judgment of individuals has been proven by Allcott and Dubinsky. Through the controlled investigation, the number of customers who choose energy-saving lights increased by $12 \%$ after being informed of the energy consumption in the lifetime of incandescent lamps and energy-saving lights [17]. The peer effect was validated by Bollinger and Gillingham. The number of installed photovoltaic systems considerably encourages the number of newly installed ones in the same region [18]. Korcaj et al. discovered that the influence of social norm is one of the key elements in household photovoltaic systems purchases. To put it in another way, the green behavior of communities, neighborhoods or relatives positively impacts on personal behavior and decision-making as a normative effect [19]. In addition, some perspectives in prototyping the process automation with light IT systems, green energy labelling with eco-design and the environmental-economical integrated analysis are all of vital importance to economically, environmentally and electrically promote the renewable energy storage system currently in a separate paradigm [20-23].

This paper aims to apply behavioral economics to power system improvement, using behavioral economics to generate incentive effect for users, and guiding users to purchase household battery storage. Moreover, the energy dispatching strategy optimization was carried out by multi-objective genetic algorithm, with peak load shifting and economic benefits as the optimization objectives, so as to improve the friendly interaction between the users and the grid. The objective of this paper is, with the dual-goal of enhancing the power system stability under behavioral economics and providing incentives for 
consumers, to acquire household battery energy storage. In addition, a multi-objective genetic algorithm is adopted to optimize energy dispatching strategies with peak load shifting and economic advantages as objective goals, as a promotion for user-to-grid interaction. The novel behavioral economics-based power grid optimization strategy combines the user experience with the traditional grid management idea as a preliminary but promising guidance for a highly green, accessible and steady renewable energy storage system in the future.

\section{Methodology}

This paper aims to integrate the behavioural economics into the optimization strategy of the power system with a household battery energy storage system. There are mainly two parts to this paper (in Figure 1): (1) the empirical study and (2) the dispatch strategy optimization. The empirical study provides the guidance for the parameter setting on the scale of household battery energy storage of dispatch strategy to be further optimized. That is, the behavioural economics incentives serve as the input of the power system with the household battery energy storage system, while the optimized dispatch strategy is the output.

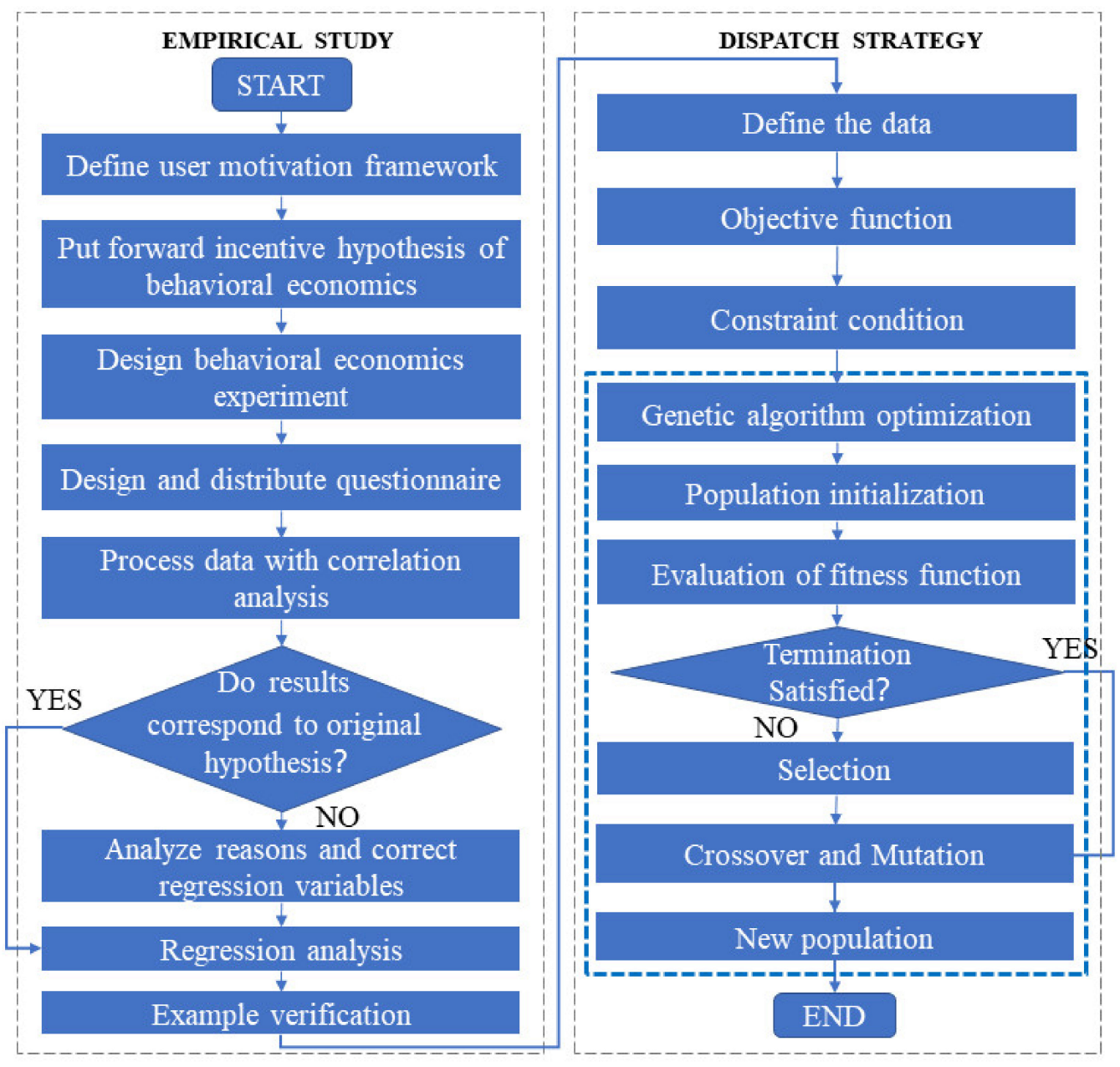

Figure 1. Research methodology and framework.

For the empirical study, the user motivation framework is proposed to study the effect of behavioural economics, where the gain goal, normative goal and hedonic goal are considered as the dominating factors that constitute the behavioral economics model. In order to study the impact of the behavioral economics on the purchase intention, the hypothesis on gain goal, normative goal and hedonic goal are formulated, respectively. 
The questionnaire is designed and distributed to collect the primary data by randomly asking the interviewee questions with controlled behavior incentives (i.e., the incentive condition may randomly change according to the set conditions). To ensure an acceptable confidence level in the context of statistics, a correlation analysis is also conducted. Finally, the relationship between the user motivation and the purchase intention on household battery energy storage is formulated by a regression analysis.

For the dispatch strategy optimization, the parameter for the case study is set with controlled behavior incentives (i.e., two case scenarios are set as baseline conditions and behavioral incentives-involved conditions, respectively). The objective functions to be optimized are set as user revenues and the grid variance. For the optimization process involving multi objective functions, the multi genetic algorithm (NSGA-II) is adopted for good convergence ability. To simplify the solving procedure, the basic manipulation of population initialization, fitness evaluation, tolerance, elite selection, crossover and mutation is set in the built-in toolbox in MATLAB.

\section{Behavioral Economics Incentive Model}

\subsection{User Motivation Framework}

Human behavioral decisions are driven by motivations. The goal-framing theory stipulates that users' behavioral motivations can be classified into three basic components: gain, normative and hedonic goal [24]. In terms of household battery storage, the motivations correspond to the economic return on peak-load shaving arbitrage, social norms in the tendency of following the others and spiritual incentives as a self-honour from green behaviour, respectively. According to the principles of behavioral economics, the present bias, herd effect and intrinsic motivation are used to stimulate the effect of users' behavioral motivations on the household battery energy storage purchase intention. On these bases, we integrate the emerging insights of both battery energy storage and user's behavioral economic incentives into an overall framework to describe the model of behavioral economics incentives. As is shown in Figure 2, the proposed behavioral economics incentive-based household battery energy storage framework aims to facilitate the peak-load shaving, energy conservation, accommodation, emergency response with the dual purpose of flexibility and economy.

\section{Behavior Incentive Model}

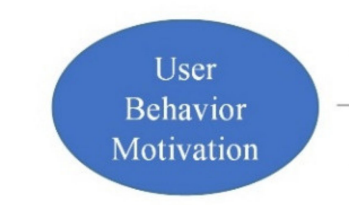

Innovation Incentive

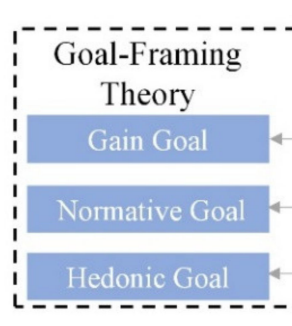

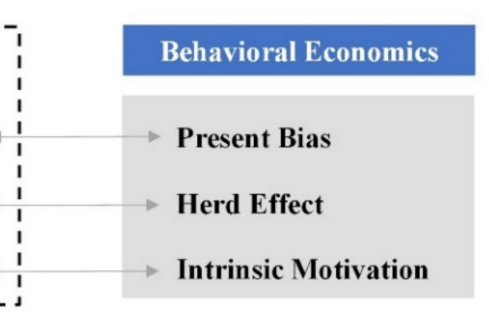

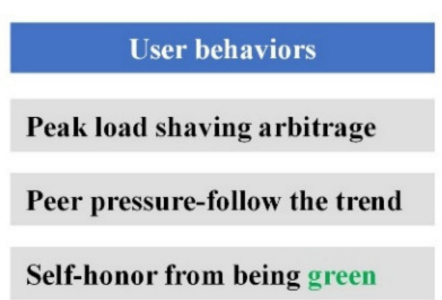

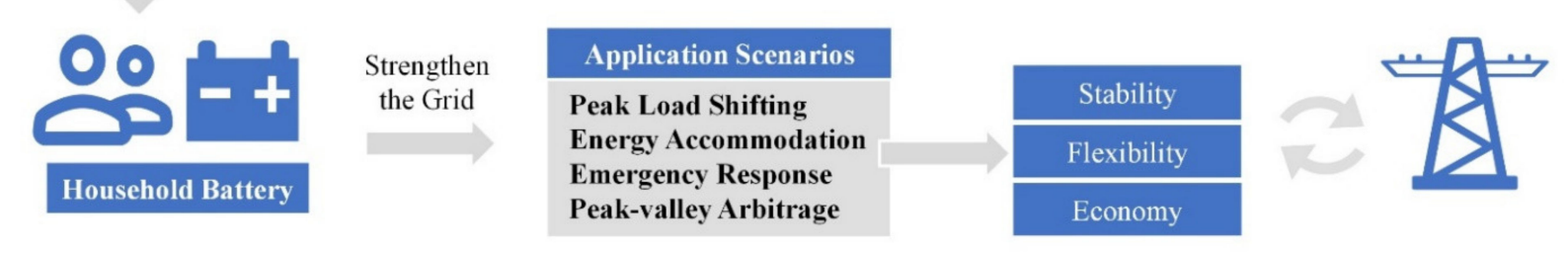

Figure 2. The model of behavioral economics incentive.

\subsection{Hypothesis Development}

This section aims to formulate the potential research questions (hypothesises) under the user motivation framework proposed. To be specific, the effect of gain goal, normative 
goal and hedonic goal on household battery energy storage purchase intention in terms of behavioral economics are considered. To date, there are several researches on the integration of economic incentives and renewable energy storage systems. The combination of photovoltaic energy storage systems and economic incentives can reduce the share of electricity demand from the grid side to 25-35\% [14]. Dietrich believes that economic incentives is a key factor affecting the investment in user-side photovoltaic energy storage systems [13]. From the perspective of behavioral economics, the gain goal substantially influences user purchasing decisions. The behavioral economics also indicates that individuals are inclined to compromise or even assimilate, which is the herd effect. Although Bollinger and Gillingham have verified the influence of the peer effect, where their conclusion showed that the number of installed PV significantly promoted the number of new PV in the same area [18]. Likewise, the users' intention to purchase household battery energy storage may imitate the positive-feedback paradigm as an essence of the herd effect. On this basis, it is possible to define normative goal as a result of the herd effect from green, low-carbon behaviors of surrounding friends, neighbors or communities on individual behavior and decision-making on the household battery energy storage. Another aspect of the behavior economics is quite interesting in that the extra energy-saving reminder by simply installing a read warning light should empower an energy conservation up to $40 \%$ during peak hours [16]. Allcott and Dubinsky found through a randomized controlled experiment study that after informing consumers of the energy consumption potential of different appliances (i.e., the incandescent lamps and energy-saving lamps), a $12 \%$ increase of the consumers tended to choose energy-saving lamps [17]. It is suggested by behavioral economics that individuals' decision-making will be affected by psychological and behavioral preferences. In the context of energy conservation, the hedonic motivation of environmental awareness consequentially affects household battery energy storage purchase intention. Based on the aforementioned analysis, it thereby comes to the following three Hypotheses:

Hypothesis 1. The gain goal in terms of behavioral economics has a positive incentive effect on household battery energy storage purchase intention.

Hypothesis 2. The normative goal in terms of behavioral economics has a positive incentive effect on household battery energy storage purchase intention.

Hypothesis 3. The hedonic goal in terms of behavioral economics has a positive incentive effect on household battery energy storage purchase intention.

\subsection{The Behavioral Economics Incentive-Controlled Experiment}

To study the users' purchase intention of battery, a user incentive model with three components of gain goal, normative goal and a hedonic goal is established. Based on behavioral economics principles such as present bias, herd effect and intrinsic motivation relating to the real-world user behaviors, this paper designs a control experiment for these three kinds of motivation, and tests the influence on user motivation. Furthermore, the influence of behavioral economics on purchase intention is evaluated. The above variable control experiments are tested by a scale questionnaire, which is commonly adopted in the behavioral economics and psychophysics experiments of Nobel Prize winners Daniel Kahneman and Vernon Smith [25]. Scales can transform abstract and subjective expressions into quantitative objective data. The variables and their corresponding definitions are listed in Table 1. The questionnaire was distributed in China, with underdeveloped areas such as Tibet and Xinjiang excluded for their potentially poor access to the state-of-the-art technologies. Considering the impact of COVID-19, the questionnaire was distributed via the Internet. The Internet channels used included WeChat social platforms and mailboxes. To ensure the authenticity of the questionnaire, repeated answers and false answers were forbidden by technical measures. Moreover, IP (internet protocol) and device restrictions 
were implemented for potentially redundant data. The survey time was from 20 December 2020 to 27 December 2020, and a total of 381 questionnaires were collected.

Table 1. Variables and definition.

\begin{tabular}{|c|c|c|}
\hline Variables & Class & Definition \\
\hline \multicolumn{2}{|r|}{ Demography } & Age, gender, education level, income \\
\hline \multirow{2}{*}{$\begin{array}{l}\text { Product } \\
\text { attitude }\end{array}$} & Info. access & Information access to green and renewable energy systems \\
\hline & Environmental. friendliness & $\begin{array}{c}\text { Recognition of environmental protection and } \\
\text { renewable energy }\end{array}$ \\
\hline \multirow{3}{*}{$\begin{array}{l}\text { User } \\
\text { attitude }\end{array}$} & Gain & $\begin{array}{c}\text { Recognition of the economic benefit of energy } \\
\text { storage products }\end{array}$ \\
\hline & Normative & $\begin{array}{c}\text { Recognition of the social popularity of energy } \\
\text { storage products }\end{array}$ \\
\hline & Hedonic & $\begin{array}{c}\text { Recognition of the green attributes of energy } \\
\text { storage products }\end{array}$ \\
\hline \multicolumn{2}{|c|}{ Purchase intention } & Intention to purchase energy storage products \\
\hline
\end{tabular}

(1) Questionnaire design (see Appendix A for detailed information): The questionnaire includes incentive control experiments based on the three factors of the user motivation framework and behavior economics, and questions of demography. The overall design adopts Ozaki's questionnaire design [26]. Some of the scale questions were designed with the questionnaire on relevant studies of electric vehicles [27].

(2) Data collection: According to the three types of incentive conditions, a total of 8 groups were set, with 40-50 people in each group.

(3) Data analysis and processing: SPSS 22 was used for statistical analysis. Reliability analysis, correlation analysis and regression analysis were conducted.

\subsection{User Incentive Model Formation}

A total of 381 questionnaires were collected and 327 of them were used for further analysis after screening. In Table 2, among the valid 327 interviewees, the average age was 30.6. The male (female) ratio is $51.7 \%(48.3 \%)$, and the gender distribution was relatively even. The family income level was relatively high, with an annual income of more than 100,000 -yuan (300,000-yuan) accounting for $82.3 \%$ (some $20 \%$ ). This potentially resulted from the fact that the questionnaires were sent to areas with a higher level of economic development. The education level was mainly college and undergraduate, accounting for $68.2 \%$. The overall education level of the questionnaire respondents was relatively high. This may be attributed to the cutting-edge feature of the household energy storage products, thereby, people with a higher level of knowledge were more likely to be interested in answering this questionnaire. In terms of regional distribution, the interviewees were mainly from first- and second-tier cities, which is consistent with the potential market for household battery energy storage. 
Table 2. The constitution of the demographic data.

\begin{tabular}{ccc}
\hline Variable & Unit & Statistical Data \\
\hline EE & Years old & 30.6 \\
Sex ratio: male & $\%$ & 51.7 \\
Sex ratio: female & $\%$ & 48.3 \\
Family annual income & CNY & \\
$>300,000$ & $\%$ & 19.3 \\
100,000-300,000 & $\%$ & 63.0 \\
$<100,000$ & $\%$ & 17.7 \\
Education level & $\%$ & 26.6 \\
Master's degree or above & $\%$ & 68.2 \\
College or undergraduate degree & $\%$ & 5.2 \\
High school or below & $\%$ & 52.3 \\
City of residence & $\%$ & 28.1 \\
1st-tier cities & $\%$ & 12.8 \\
2nd-tier cities & $\%$ & 4.9 \\
3rd-tier cities & $\%$ & 1.8 \\
County seats & $\%$ & \\
Rural area & $\%$ & \\
\hline
\end{tabular}

In terms of user attitudes, information access (4.55/7) and green attitude (5.53/7) were higher, which is consistent with a higher income and educational background. The high income and high education levels are reasonable in this paper. The main reason for them is that household energy storage is mainly used in developed areas of the first and second tier cities, where people with environmental awareness and a certain level of knowledge are interested in reaching the questionnaire. E. Vigants et al. also observed a similar phenomenon in their use behavior research. In terms of product attitudes, the user motivation indicators are overall moderate, with the behavioral economics excited values indicated in the round brackets in Table 3. Among them, the gain goal is 4.64 above average, which reflects that the household energy storage rate of return presented in the questionnaire is acceptable to most people. The average level of normative goal is low. This may be because household energy storage has a low penetration rate in most areas of China, and users have a weaker perception of its true nature. The hedonic goal index is 4.78 , which is higher than the other two. This reflects the recognition of the green and environmentally friendly attributes of household energy storage, which may be related to the population's higher green attitude. The overall intention to purchase the rate of users increases from $55.74 \%$ to $61.85 \%$ by applying behavioral economics incentives, indicating an increase ratio of $10.97 \%$.

Table 3. The statistical description of the variables in the behavioral economics-controlled experiment.

\begin{tabular}{ccccc}
\hline Variables & Minimum & Maximum & Mean & Standard Error \\
\hline Information access & 1.00 & 7.00 & 4.55 & 1.67 \\
\hline Green attitude & 2.7 & 7.00 & 5.53 & 0.62 \\
\hline Gain goal & $1.00(1.00)$ & $7.00(7.00)$ & $4.64(4.93)$ & $1.25(1.24)$ \\
\hline Normative goal & $1.00(1.00)$ & $7.00(7.00)$ & $3.55(4.19)$ & $1.59(1.46)$ \\
\hline Hedonic goal & $1.00(1.00)$ & $7.00(7.00)$ & $4.78(5.11)$ & $1.47(1.29)$ \\
\hline Purchase intention & $6.00(16.00)$ & $100.00(100.00)$ & $55.74(61.85)$ & $22.30(20.76)$ \\
\hline
\end{tabular}

In the questionnaire, there is a behavioural economics incentive-controlled condition. The collected data contains the potential information of behavioural economics incentives for purchase intention. However, the setting of the questionnaire is sensitive to factors such as the sample size, the specific individuals being interviewed, and the degree of economic development in the survey region. Therefore, it is necessary to analyse the validity of the data collected by the questionnaire. This paper uses a $t$-test to determine 
whether behavioural economics incentives will have a significant relationship on gain goal, normative goal, and hedonic goal (i.e., the question being asked is suitable to evaluate the parameters under the user motivation framework). In the $t$-test, $\mathrm{T}$ and $p$ are the notations for t-statistic and $p$-values, respectively. The $T$ is statistically essential to describe the significant relationship between the collected sample data, and $p$ is the confidence level to reject the hypothesis. In addition, the relationship between $\mathrm{T}$ and $p$ can be retrieved in the look-up table for the critical value of $t$-test. To be specific, the current bias is significantly related to gain goals $(p=0.034<0.05)$. The herd effect is significantly related to normative goals $(p=0.000<0.05)$. The intrinsic motivations are significantly related to hedonic goals $(p=0.030<0.05)$. As a result, the data in Table 4 confirm that the incentive-controlled condition in the questionnaire shows the statistically significant relationship between the three dimensions of the user motivation framework and the variables assigned in the questionnaire without causing cross-effects. The designed variables in controlled incentives consequentially serve as a valid measure for the gain goal, normative goal and hedonic goal, which supports the user motivation framework proposed.

Table 4. Correlation analysis of variables.

\begin{tabular}{ccccccc}
\hline \multirow{2}{*}{ Model } & \multicolumn{2}{c}{ Present Bias } & \multicolumn{2}{c}{ Herd Effect } & \multicolumn{2}{c}{ Intrinsic Motivation } \\
& $\mathbf{T}$ & $\boldsymbol{p}$ & $\mathbf{T}$ & $\boldsymbol{p}$ & $\mathrm{T}$ & $\boldsymbol{p}$ \\
\hline Gain goal & -2.127 & $0.034 *$ & -1.491 & 0.137 & -0.043 & 0.965 \\
Normative goal & -0.693 & 0.489 & -3.784 & $0.000 *$ & -0.077 & 0.939 \\
Hedonic goal & -0.217 & 0.828 & 0.558 & 0.577 & -2.177 & $0.030 *$ \\
Purchase probability & 0.537 & 0.592 & -1.056 & 0.292 & -0.838 & 0.403 \\
\hline * Symbol stands for statistically sionificant.
\end{tabular}

* Symbol stands for statistically significant.

Since the collected data are valid for the measurement of the gain goal, normative goal and hedonic goal under the user motivation framework, the purchase intention on the household battery energy storage can be further quantitatively presented by conducting a regression analysis. The linear regression equation regarding the purchase intention and the factors under user motivation framework can be consequentially formulated as:

$$
F_{i}=\alpha_{0}+\beta_{1} G_{i}+\beta_{2} N_{i}+\beta_{3} H_{i}+\varepsilon_{i}
$$

where, $F_{i}$ is purchase probability, $G_{i}$ is gain goal, $N_{i}$ is normative goal, $H_{i}$ is hedonic goal and $\varepsilon_{i}$ is the relaxation term (constant).

The user incentive model is derived by solving the linear regression equation. As is shown in Table 5, the linear regression equation fits well with the gain goal, normative goal and hedonic goal with $\mathrm{R}^{2}=0.621>0.6$. The linear regression equation (user incentive model) is as the following:

$$
F=6.338 G+2.882 \mathrm{~N}+7.009 \mathrm{H}-17.307
$$

This indicates that the gain goal, normative goal and hedonic goal under the user motivation framework interpretate the purchase intention as a positive effect, respectively. Additionally, the $t$-test indicates a significance value lower than 0.05 . Consequentially, the positive correlation between the user motivation framework and the purchase intention is trustable at the $95 \%$ confidence level. As for the multi co-linearity, VIF (variance inflation factor) is also applied to test the independence of each selected variable. It is normally acceptable that there is no multi co-linearity when VIF is less than 10. This further verified that the gain goal, normative goal and hedonic goal under the user motivation framework can be considered as independent variables to ensure the goodness of the user incentive model. Based on the above analysis, the overall linear relationship between the user motivation framework and purchase intension stands confidently by conducting $F$-test $(F=149.164, p<0.001)$. As a result, the user motivation framework can be effectively adopted as a measurement for purchase intention on household battery energy storage with good independence and robustness. 
Table 5. Multiple variable linear regression.

\begin{tabular}{|c|c|c|c|c|c|c|}
\hline \multirow{2}{*}{ Model } & \multicolumn{2}{|c|}{$\begin{array}{c}\text { Ustd. } \\
\text { Coefficient }\end{array}$} & \multirow{2}{*}{$\begin{array}{c}\text { Std. } \\
\text { Coefficient } \\
\text { Beta }\end{array}$} & \multirow[t]{2}{*}{$\mathbf{t}$} & \multirow[t]{2}{*}{ Sig. } & \multirow[t]{2}{*}{ VIF } \\
\hline & B & SE & & & & \\
\hline Constant & -17.307 & 3.764 & & -4.598 & 0.001 & \\
\hline Gain & 6.338 & 0.784 & 0.340 & 8.080 & 0.000 & 1.367 \\
\hline Normative & 2.882 & 0.608 & 0.194 & 4.743 & 0.000 & 1.290 \\
\hline Hedonic & 7.009 & 0.704 & 0.420 & 9.961 & 0.000 & 1.369 \\
\hline \multicolumn{4}{|c|}{$\mathrm{R}^{2}$} & \multicolumn{3}{|c|}{0.621} \\
\hline \multicolumn{4}{|c|}{$F$} & \multicolumn{3}{|c|}{149.164} \\
\hline \multicolumn{3}{|c|}{$p$} & & \multicolumn{3}{|c|}{$<0.001$} \\
\hline
\end{tabular}

\section{Optimization of Household Battery Dispatching}

The purchase intention of household battery energy storage is effectively incentivized under behavioral economics. This paper uses the multi-objective genetic algorithm to verify the impact on both the power grid and users. The optimization is implemented under a renewable energy accessible community where peak load shifting is carried out for arbitrage. Furthermore, the effectiveness of behavioral economics incentives in both grid variance and user revenues is validated by comparing the optimization results under different case parameter settings (i.e., with and without behavioral economics incentives).

\subsection{Case Description}

The case study of this article takes a Chinese new energy community as an example. Its power system is composed of grid, distributed energy, load and energy storage system. The community has adopted a time-of-use electricity price system. The total capacity of the household energy storage system installed in community is up to $2 \mathrm{MWh}$, and the total rated power is $0.5 \mathrm{MW}$ [28]. This paper sets scenario 1 (Case1) and scenario 2 (Case2). Scenario 1 is the baseline situation of the community. Scenario 2 is the community situation after applying behavioral economics incentives. The overall intention to purchase intention increases from $55.74 \%$ to $61.85 \%$ by applying behavioral economics incentives, indicating an increase ratio of $10.97 \%$ according to the empirical study. On this basis, the total energy storage capacity in Case 2 is thereby set as $2.22 \mathrm{WMh}$ (corresponding to an $10.97 \%$ increase from the baseline) in Table 6 . In order to study the role of household battery storage in this community, the data of daily load and electricity price are extracted, as shown in the Figure 3. The daytime is divided into 96-time nodes, with interval of $15 \mathrm{~min}$.

Table 6. Case settings under behavioral economics incentives-controlled experiment.

\begin{tabular}{cccc}
\hline Situation & Capacity & Power & SOC \\
\hline Case1 & $2 \mathrm{MW}$ & $-0.45 \sim 0.45 \mathrm{MW}$ & $10 \% \sim 90 \%$ \\
Case2 & $2.22 \mathrm{MW}$ & $-0.50 \sim 0.50 \mathrm{MW}$ & $10 \% \sim 90 \%$ \\
\hline
\end{tabular}




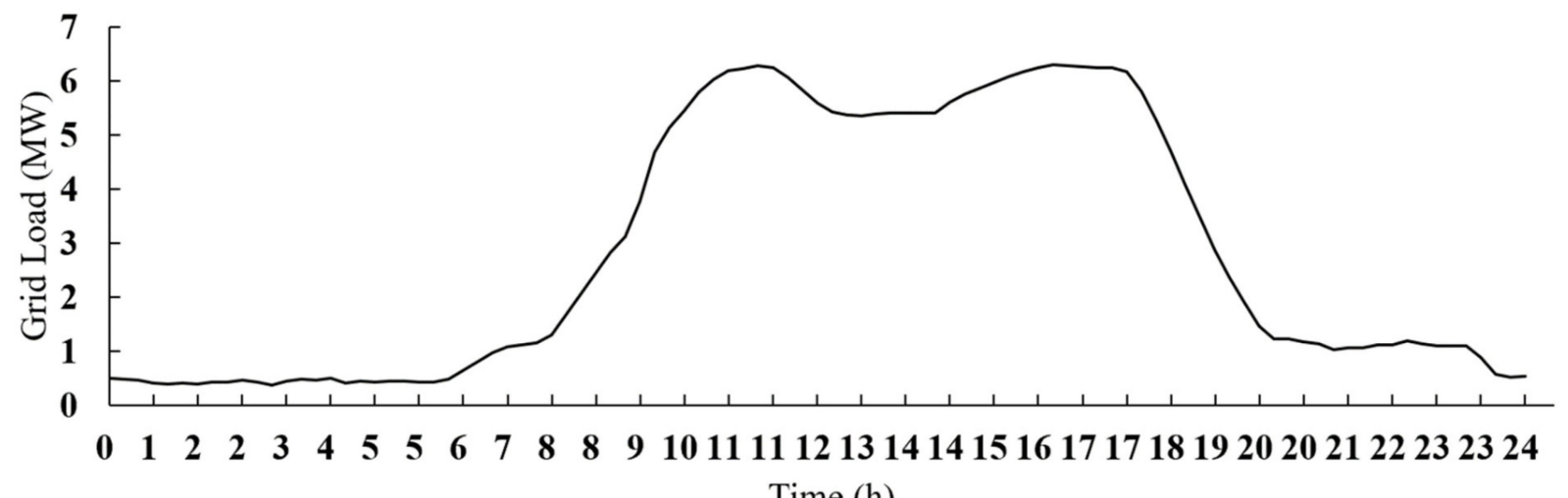

Time (h)

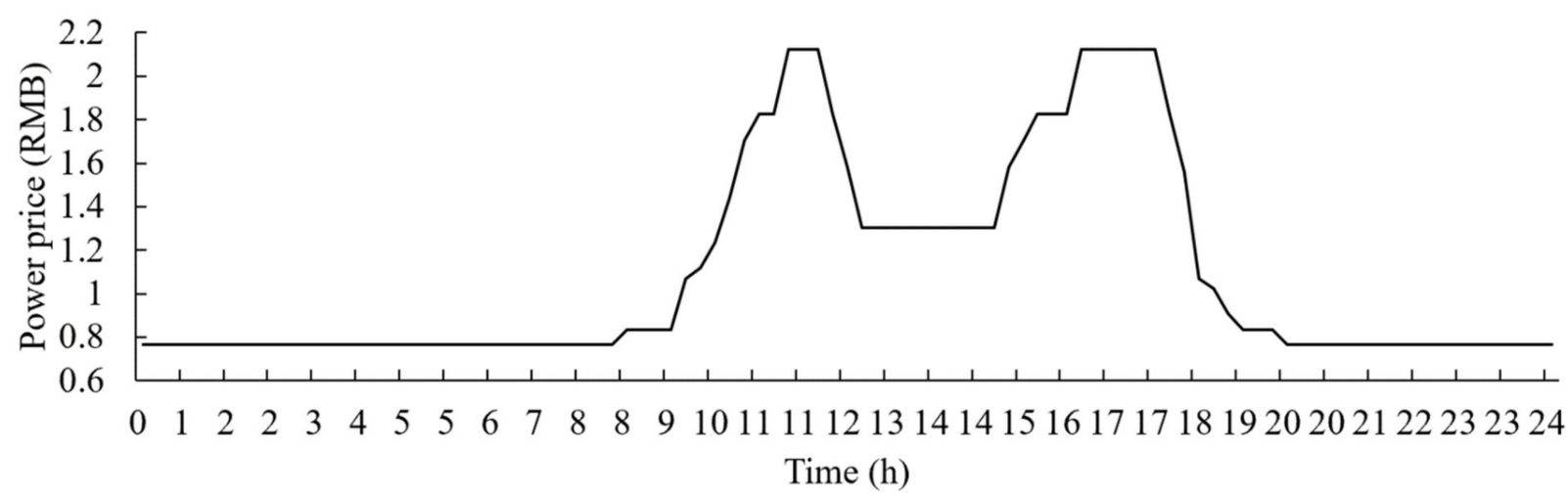

Figure 3. Grid load and power price.

\subsection{Objective Function}

The following objective functions to be optimized are set as grid stability and user revenue.

Grid stability: battery storage regulates the peak and valley load. With the grid stability considered, the grid variance is expressed as Equation (3):

$$
\min F_{1}=\frac{1}{T} \sum_{t=1}^{T}\left[\left(P_{t, l o a d}-P_{t, \text { ess }}\right)-\frac{1}{T} \sum_{t=1}^{T}\left(P_{t, \text { load }}-P_{t, e s s}\right)\right]^{2}
$$

where, $P_{t, \text { load }}$ is the power grid load at time $t, P_{t, e s s}$ is the battery power at time $t$ (negative for discharging and positive for charging). $T$ is the sampling periods with 96 nodes.

User revenue: the peak load shifting is applied for arbitrage under the time of use electricity price system. The user revenue is derived as Equation (4):

$$
\max F_{2}=\sum_{t=1}^{T} 1000 \Delta t \cdot P_{t, e s s} \cdot e_{t}
$$

where $\Delta t$ is the time interval of $15 \mathrm{~min}, e_{t}$ is the power grid price (RMB/Yuan).

\subsection{Constraints}

For this paper, the electrical topology is unconsidered for simplicity. Only the constrains related to the battery energy storage system are taken into consideration.

Power constraint: the optimization process is terminated when the operation limit of the battery energy storage system is hit. The power constrain is expressed as Equation (5):

$$
P_{t, \min } \leq P_{t, e s s} \leq P_{t, \max }
$$


SoC (State of Charge) constraint: $S O C_{\min }$ is the minimum remaining capacity of the battery storage system, $S O C_{\max }$ is the maximum remaining capacity of the battery storage system, $10 \%$ and $90 \%$ are taken in this paper.

SoC (State of Charge) constraint: for safety operation of the battery energy storage system, 10\% and 90\% are set as lower and upper limit. The SOC constrain is expressed as Equation (6):

$$
S O C_{\min } \leq S O C \leq S O C_{\max }
$$

\subsection{Optimization Strategy}

This paper adopts a multi-objective genetic algorithm to solve the real-time charging/discharging power of the battery energy storage system. The mutation and crossover manipulation are implemented by using built-in function mutationadaptfeasible and crossoverintermediate in MATLAB,(2021a, MATHWORKS, MA, USA) respectively. The population size, evolutionary generation, constraint tolerance and objective function tolerance is $400,10,000,10^{-3}$ and $10^{-6}$, respectively. When the iteration comes to 3415 generation, objective function tolerance converges to $10^{-6}$. The case settings for dispatch optimization are listed in Table 7.

Table 7. Case settings for dispatch optimization.

\begin{tabular}{ccccccc}
\hline Situation & Capacity & Power & SOC & $\zeta$ & $\boldsymbol{~} \mathbf{t}$ & T \\
\hline Case1 & $2 \mathrm{MW}$ & $0 \sim 0.45 \mathrm{MW}$ & $10 \% \sim 90 \%$ & 0.9 & $15 \mathrm{~min}$ & 96 \\
Case2 & $2.22 \mathrm{MW}$ & $0 \sim 0.50 \mathrm{MW}$ & $10 \% \sim 90 \%$ & 0.9 & $15 \mathrm{~min}$ & 96 \\
\hline
\end{tabular}

\subsection{Results and Discussion}

As was previously illustrated in Figure 1, the multi-objective optimization is implemented. The optimized strategy indicates a featured charging/discharging behavior, where 0-7 $\mathrm{h}$ and 9-12 $\mathrm{h}$ are taken as discharging hours preferentially. Meanwhile, optimized strategy also indicates a low-power charging at 12-14, followed by a discharge in period 14-18 and a charge in period 18-24 (in Figure 4).
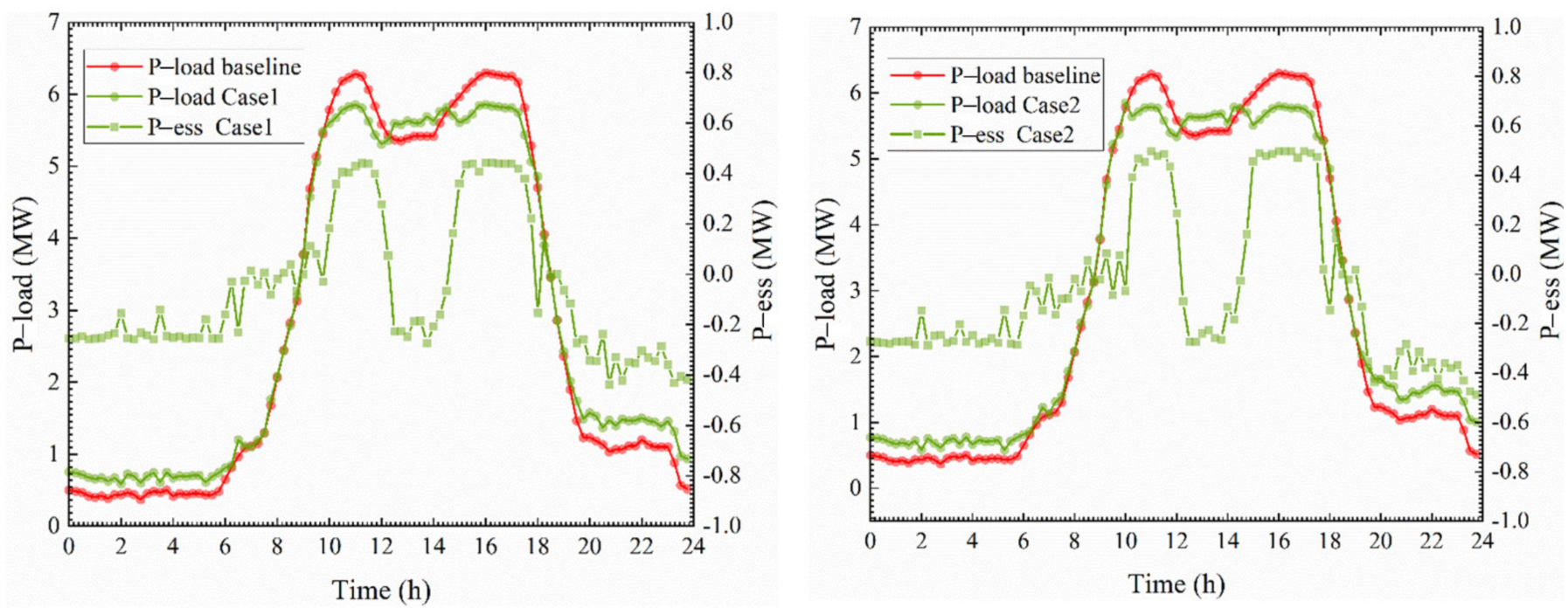

Figure 4. Power grid load and battery storage power under Case1 and Case2.

The Pareto optimal solution set is obtained solving with multi-objective optimization problems. As can be seen from the Pareto Front (Figure 5), the variance decreases with profit. However, variance and profit vary little; that is, pareto optimal solutions are very concentrated. It can be understood that the two optimization objectives of this scheme are consistent in the global scheduling (since the electricity price is positively correlated 
with the peak and valley of load, the variance is reduced and the profit is maximized in the process of peak and valley shifting). This phenomenon is reasonable. The price system based on market supply and demand will encourage the behavior of participating in the maintenance of grid stability, and the more unbalanced the supply and demand is, the stronger the incentive will be. However, the grid variation and user revenue vary little, which is extremely focused on Pareto optimum solutions. It is clear that the two optimization goals in current case settings are consistent with the global planning. This is resulted from the fact that the gird variance is reduced and the profit is maximized in the process of peak and valley shifting. That is a plausible phenomenon, since the time of use electricity price system is according to the peak and valley. The pricing system based on the supply and demand markets will foster the grid stability under the behavioral economics incentive.

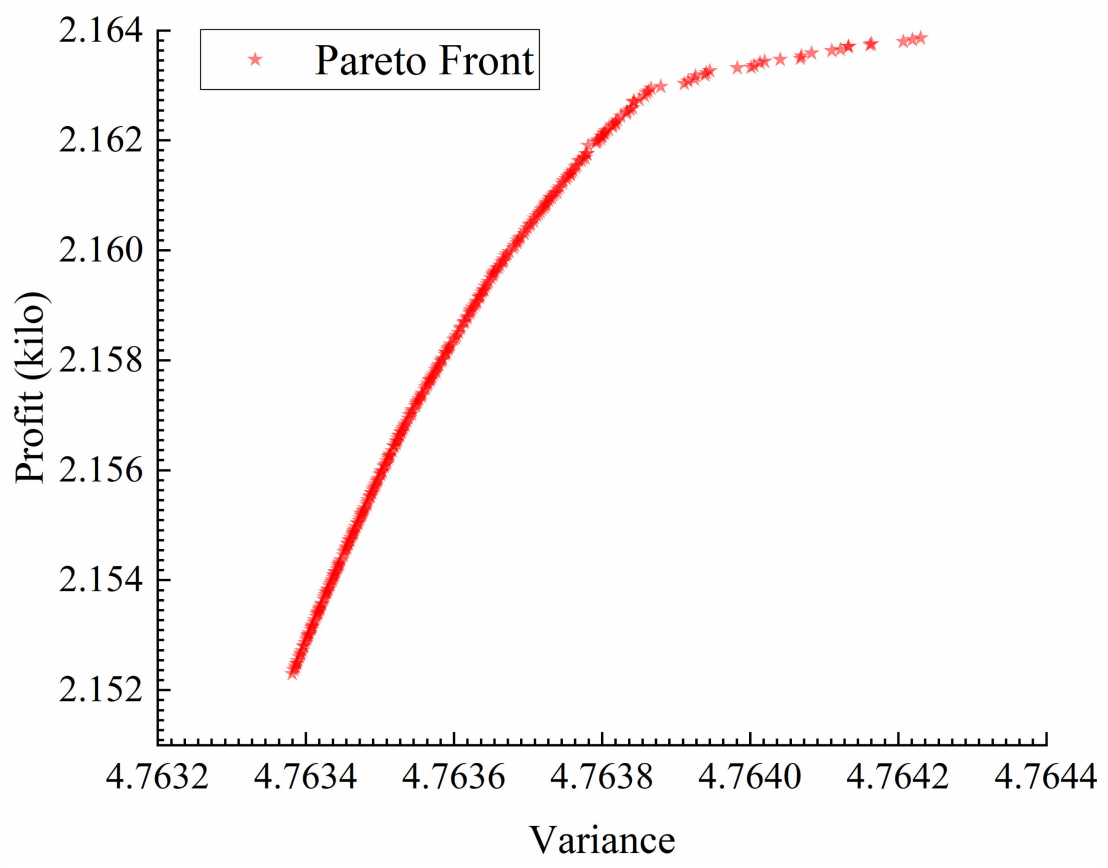

Figure 5. Pareto Front of profit V.S. variance.

The effectiveness of behavioral economic incentives is shown in Figure 6 and Table 8 . With the applied economic incentives, the total capacity and power of household battery storage are increased, indicating a better purchase intention. Moreover, the peak load shifting is of performance in grid variance. Therefore, a more uniformly distributed load curve can be observed.

- The behavioral economics incentives effectively promote both grid stability and user revenues. Under the set scenario, the purchase intention (installed capacity) is increased by $10.7 \%$, leading to a grid variance drop from 4.764 to 4.662 . With respect to the user revenue, daily profit increases by $10.5 \%$ (from 2164 to 2392 Yuan).

Table 8. Comparison of variance and revenue.

\begin{tabular}{ccccc}
\hline Situation & Capacity & Power & Variance & Revenue \\
\hline No battery & 0 & 0 & 5.640 & 0 \\
Constant power & $2 \mathrm{MWh}$ & $\pm 0.45 \mathrm{MW}$ & 5.124 & 1996 \\
Case1 & $2 \mathrm{MWh}$ & Real-time & 4.764 & 2164 \\
Case2 & $2.22 \mathrm{MWh}$ & Real-time & 4.562 & 2392 \\
\hline
\end{tabular}



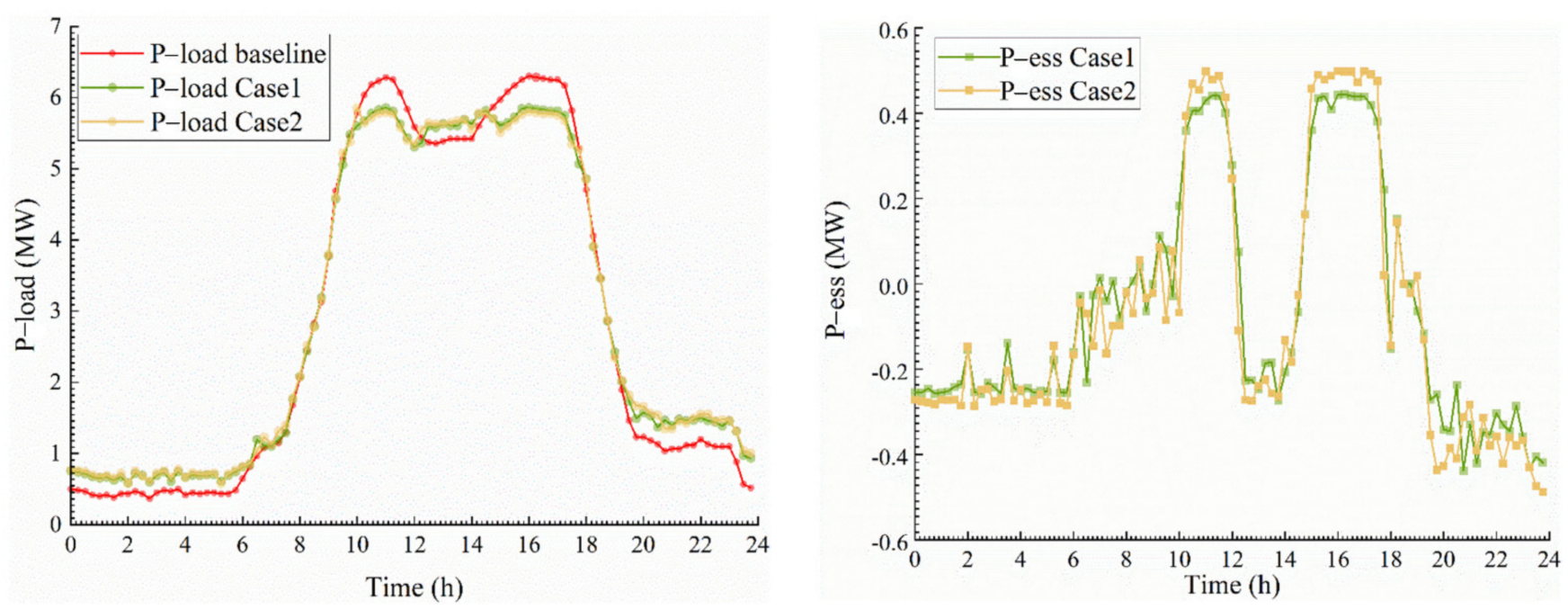

Figure 6. Comparison of grid load and battery storage power.

\section{Conclusions}

This paper conducts an empirical study to investigate behavioral economics incentives with the dual goal of power system optimization and user revenue. A user incentive model is proposed to quantitatively describe the battery energy storage purchase intention. The effectiveness of behavioral economics incentives is verified by carrying out the multiobjective optimization under behavioral economics incentives-controlled scenarios. The results indicate that:

(1) The behavioral economic incentives positively encourage the promotion of household battery storage purchase intention, without increasing economic costs. This effect is mainly achieved through users' motivation goals. Behavioral economic incentives can increase the total capacity of household battery storage, which can enhance the effect of peak load shifting and improve user benefits.

(2) The $10.7 \%$ increase in installed energy storage capacity can reduce the grid variance by $4.2 \%$ and increase user revenue by $10.6 \%$. It is proved that behavioral economic incentives can improve the stability of power grid and user benefits from energy storage.

The behavioral economic incentives proposed in this paper can effectively improve the purchase intention of household energy storage users, guide users' behavioral decisions without additional economic expenditure. Thus, the dual goals of power grid stability and user benefits are integrated as one currently in separate paradigm. It is worth noticing that the study is currently a simple application of behavioral economics to model individual behavioral decisions. Human behavior motivation is a complex system and more factors remain to be studied. Since the future behavioural economics and renewable energy system will further be integrated and coupled as a complex process, future works should concentrate on the automated assessment of the user behaviours, the health status of the electrical equipment and on green energy labelling and so on. Furthermore, energy policies should not only support the user side subsidies on household battery energy storage as a direct incentive, but also introduce both economic and environmental paradigms to build a comprehensively integrated household battery energy storage system. Understanding human behavior motivations is crucial in the analysis and modeling of power systems. The novel behavioral economics-based power grid optimization strategy combines the user experience with the traditional grid management idea as a preliminary but promising guidance for a highly green, accessible and steady renewable energy storage systems in the future. 
Author Contributions: Conceptualization, S.T. and Y.Z.; methodology, Y.Z. and Y.S.; software: R.Z. and S.T.; validation, M.Y. and Z.X.; writing-original draft preparation: Y.Z. and S.T.; writing-review and editing, M.Y., R.Z., Z.X. and Y.S.; supervision: Y.S.; project administration: Y.Z. and Y.S. All authors have read and agreed to the published version of the manuscript.

Funding: This research was funded by the Key Scientific Research Program of Shanghai (Grant No.18DZ1203305), the National Key Research and Development Program of China (Grant No. 2019YFB2103200 and No. 2018YFB1500904), Shanghai Municipal Economic and Information Commission (Grant No.202001015) and Shanghai Engineering Research Center for Artificial Intelligence and Integrated Energy System (Grand No. 19DZ2252000).

Institutional Review Board Statement: Not applicable.

Informed Consent Statement: Not applicable.

Acknowledgments: This work is supported by Institute for Six-sector Economy, Fudan University for empirical study design and implementation. It is also greatly appreciated that M.S. Ran Jin in School of Economics and Management, Tongji University contributes to the econometric and statistical validation, hypothesis development and analysis.

Conflicts of Interest: The authors declare no conflict of interest.

\section{Appendix A}

Survey on consumers' intention to purchase household energy storage

Gender:

Age:

City:

Annual Income:

Occupation:

Highest Education Level:

\section{Production Description}

Household battery energy storage (also known as household battery pack) is a household electrical energy storage device that can help families reduce electricity costs, which is conducive to stability and a low-carbon power grid. The energy storage is connected to the home circuit, and the charging/discharging operations are under the control of the power management system. The main functions of household energy storage are:

(a) Grid peak-valley arbitrage: There is a price difference between high and low electricity prices. Energy storage can be used to get profit by re-discharging: store electricity when the electricity price is low and sell to the grid or use it when the electricity price is high.

(b) Home power reserve: When encountered with an unexpected power failure, the energy stored in the energy storage can continue to supply energy for the family.

(c) Participate in grid dispatching: Maintaining the stability of the grid, which can reduce the cost of power generation and carbon emissions of the grid, and contribute to green environmental protection.

\section{Product Prices and Profits}

If a certain energy storage equipment sells for 40,000 CNY (13.5kWh, 10-year life).

According to a subsidy of $1 \mathrm{CNY} / \mathrm{kWh}$ for energy storage in some areas of China, the peak-to-valley arbitrage of this equipment can bring about $5500 \mathrm{CNY}$ of economic benefits each year. 
Do you know or are using "household energy storage" equipment?

\begin{tabular}{ccccccc}
\hline Not at All & & & & \multicolumn{2}{c}{ Know Well or Using Now } \\
\hline 1 & 2 & 3 & 4 & 5 & 6 & 7 \\
\hline
\end{tabular}

Given the conditions:

*** This part is blind to the interviewees when the questionnaire is distributed:

Baseline conditions (a), (c) and (e) serves as a bassline for none behavioral economics involved, while incentive conditions (b), (d) and (f) functions as a behavioral economics incentive. The baseline conditions are always visible for any interviewees. On the contrary, the incentive conditions are randomly visible as an ADDITIONAL condition to simulate behavioral economics incentives ${ }^{* * *}$

(a) Economic benefit: The peak-to-valley arbitrage of this equipment can bring about $5500 \mathrm{CNY}$ of economic benefits per year;

(b) If the annual income of $5500 \mathrm{CNY}$ is deposited in the bank, the total return in 10 years can reach 62,400 CNY (56\% profit, $4.5 \%$ annualized rate of return).

If 40,000 CNY is used to deposit in a bank or buy national bonds, the annualized interest rate is about $3.5 \%$, and the total principal and interest in ten years can reach 56,400 CNY (40\% profit, 3.5\% annualized rate of return).

(c) User popularity: Energy storage equipment has been promoted and used in your community, and currently about $20 \%$ of households have purchased and used it.

(d) User popularity: Energy storage equipment has been promoted and used in your community, and currently about $50 \%$ of households have purchased and used it.

(e) Green and environmental protection: energy storage equipment contributes to energy saving and emission reduction, which can also promote the use of renewable energy, reduce power generation costs and reduce carbon emissions.

(f) Green credit on your social media: The green credit is determined by the contributions you made for power grid dispatching. Your green contribution is evaluated on the ranking list with the green credit. Your ranking is visible and can be thumbed-up by all the follow-ups.

What do you think of the economic benefits of the energy storage products?

\begin{tabular}{cccccccc}
\hline Very Low & & & & \multicolumn{3}{c}{ Very High } \\
\hline 1 & 2 & 3 & 4 & 5 & 6 & 7 \\
\hline
\end{tabular}

What do you think of the social popularity of household energy storage?

\begin{tabular}{cccccccc}
\hline Very Low & & & & \multicolumn{3}{c}{ Very High } \\
\hline 1 & 2 & 3 & 4 & 5 & 6 & 7 \\
\hline
\end{tabular}

How much do you care about the green and low-carbon properties of this product?

\begin{tabular}{cccccccc}
\hline Very Low & & & & \multicolumn{3}{c}{ Very High } \\
\hline 1 & 2 & 3 & 4 & 5 & 6 & 7 \\
\hline
\end{tabular}

Are you willing to buy this household energy storage equipment? (\%)

\begin{tabular}{cccccc}
\hline $\begin{array}{c}\text { Absolutely } \\
\text { not (0) }\end{array}$ & & & & $\begin{array}{c}\text { Most Likely } \\
\text { (100) }\end{array}$ \\
\hline 0 & 20 & 40 & 60 & 80 & 100 \\
\hline
\end{tabular}


Which of the following concepts or statements do you know well? (Multiple choice questions)

Green energy (includes photovoltaic, wind power and hydropower, etc.)

Peak-to-valley price of electricity (Time-of-use pricing system)

Grid peak shaving and valley filling

Energy storage can be used for energy storage.

Green energy contributes to low carbon emission reduction.

Photovoltaic (The principle of photovoltaic power generation)

Electromagnetic induction (The principle of wind power generation)

How do you agree with the following statements?

\begin{tabular}{lllllll}
\hline 1 & 2 & 3 & 4 & 5 & 6 & 7 \\
\hline \multicolumn{7}{c}{ Renewable energy can reduce carbon emissions } \\
\hline
\end{tabular}

Maintaining a green environment requires everyone's efforts

Low-carbon behavior is worthy of respect

Low-carbon behavior requires additional costs

Electricity prices should be as low as possible

I am willing to take energy-saving and low-carbon behaviors

I am willing to increase expenses to protect the environment

Thank you for your time and effort!

\section{References}

1. Zhou, L.; Huang, Y.; Guo, K.; Feng, Y. A survey of energy storage technology for micro grid. Power Syst. Prot. Control. 2011, 39, 147-152.

2. Junior, P.R.; Rocha, L.; Morioka, S.; Bolis, I.; Chicco, G.; Mazza, A.; Janda, K. Economic Analysis of the Investments in Battery Energy Storage Systems: Review and Current Perspectives. Energies 2021, 14, 2503. [CrossRef]

3. Wong, L.A.; Ramachandaramurthy, V.K. Optimal Battery Energy Storage System Placement using Whale Optimization Al-gorithm. Int. J. Electr. Electron. Eng. Telecommun. 2020, 9, 268-272.

4. Alsaidan, I.; Alanazi, A.; Gao, W.; Wu, H.; Khodaei, A. State-Of-The-Art in Microgrid-Integrated Distributed Energy Storage Sizing. Energies 2017, 10, 1421. [CrossRef]

5. Moriarty, P.; Honnery, D. Feasibility of a 100\% Global Renewable Energy System. Energies 2020, 13, 5543. [CrossRef]

6. Jankowiak, C.; Zacharopoulos, A.; Brandoni, C.; Keatley, P.; MacArtain, P.; Hewitt, N. The Role of Domestic Integrated Battery Energy Storage Systems for Electricity Network Performance Enhancement. Energies 2019, 12, 3954. [CrossRef]

7. Subramani, G.; Ramachandaramurthy, V.K.; Padmanaban, S.; Mihet-Popa, L.; Blaabjerg, F.; Guerrero, J.M. Grid-Tied Pho-tovoltaic and Battery Storage Systems with Malaysian Electricity Tariff-A Review on Maximum Demand Shaving. Energies 2017, 10, 1884. [CrossRef]

8. Hesse, H.C.; Schimpe, M.; Kucevic, D.; Jossen, A. Lithium-Ion Battery Storage for the Grid-A Review of Stationary Battery Storage System Design Tailored for Applications in Modern Power Grids. Energies 2017, 10, 2107. [CrossRef]

9. Pena-Bello, A.; Burer, M.; Patel, M.K.; Parra, D. Optimizing PV and grid charging in combined applications to improve the profitability of residential batteries. J. Energy Storage 2017, 13, 58-72. [CrossRef]

10. Kusakana, K. Optimal Economic Dispatch of Grid-Interactive Renewable Prosumers with Hybrid Storage and Peer to Peer Energy Sharing Capabilities. Int. J. Electr. Electron. Eng. Telecommun. 2021, 209-216. Available online: http://www.ijeetc.com/uploadfile/ 2021/0319/20210319033542245.pdf (accessed on 1 July 2021). [CrossRef] 
11. Zhang, Y.; Ma, T.; Campana, P.E.; Yamaguchi, Y.; Dai, Y. A techno-economic sizing method for grid-connected household photovoltaic battery systems. Appl. Energy 2020, 269, 115106. [CrossRef]

12. Schopfer, S.; Tiefenbeck, V.; Staake, T.; Schopfer, S.; Tiefenbeck, V.; Staake, T. Economic assessment of photovoltaic battery systems based on household load profiles. Appl. Energy 2018, 223, 229-248. [CrossRef]

13. Dietrich, A.; Weber, C. What drives profitability of grid-connected residential PV storage systems? A closer look with focus on Germany. Energ Econ. 2018, 74, 399-416. [CrossRef]

14. Barberis, N. Richard Thaler and the Rise of Behavioral Economics. Scand. J. Econ. 2018, 120, 661-684. [CrossRef]

15. Mauleón, I. Economic Issues in Deep Low-Carbon Energy Systems. Energies 2020, 13, 4151. [CrossRef]

16. Leonard, T.C.; Richard, H.T.; Cass, R.S.N. Improving Decisions About Health, Wealth, and Happiness; Springer: Berlin/Heidelberg, Germany, 2008.

17. Allcott, H.; Taubinsky, D. Evaluating Behaviorally Motivated Policy: Experimental Evidence from the Lightbulb Market. Am. Econ. Rev. 2015, 105, 2501-2538. [CrossRef]

18. Bollinger, B.; Gillingham, K. Peer Effects in the Diffusion of Solar Photovoltaic Panels. Mark. Sci. 2012, 31, 900-912. [CrossRef]

19. Korcaj, L.; Hahnel, U.J.; Spada, H. Intentions to adopt photovoltaic systems depend on homeowners' expected personal gains and behavior of peers. Renew. Energy 2015, 75, 407-415. [CrossRef]

20. Landi, D.; Castorani, V.; Germani, M. Interactive energetic, environmental and economic analysis of renewable hybrid energy system. Int. J. Interact. Des. Manuf. 2019, 13, 885-899. [CrossRef]

21. Landi, D.; Capitanelli, A.; Germani, M. Ecodesign and Energy Labelling: The Role of Virtual Prototyping. Procedia Cirp 2017, 61, 87-92. [CrossRef]

22. Kedziora, D.; Penttinen, E. Governance models for robotic process automation: The case of Nordea Bank. J. Inf. Technol. Teach. Cases 2021, 11, 20-29. [CrossRef]

23. Zhang, Y.; Tao, S.; Mao, Z.; Yuan, M.; Li, T.; Sun, Y. Power System Optimization Based on Behavioral Economics: The Case of Household Battery Storage. In Proceedings of the 2021 IEEE 4th International Conference on Electronics Technology (ICET), Chengdu, China, 7-May 2021; Volume 5, pp. 383-388.

24. Lindenberg, S.; Steg, L. Normative, Gain and Hedonic Goal Frames Guiding Environmental Behavior. J. Soc. Issues 2007, 63, 117-137. [CrossRef]

25. Kahneman, D.; Smith, V. Foundations of behavioral and experimental economics. Nobel Prize Econ. Doc. 2002, 1. Available online: https:/ / www.semanticscholar.org/paper/Foundations-of-Behavioral-and-Experimental-\%3A-Kahneman-Smith/85 6c11213b83c221fe1001eea3fc19e95d2f74d8 (accessed on 1 July 2021).

26. Ozaki, R. Adopting sustainable innovation: What makes consumers sign up to green electricity? Bus. Strat. Env. 2010, 20, 1-17. [CrossRef]

27. Plötz, P.; Gnann, T.; Wietschel, M. Modelling market diffusion of electric vehicles with real world driving data—Part I: Model structure and validation. Ecol. Econ. 2014, 107, 411-421. [CrossRef]

28. Shengwei, T.; Lulin, Z.; Peiwen, Z.; Meng, L. Variable Power Peak Load Shifting Strategy through Storage Battery System Based on Real-Time Electricity Price for Commercial Park. Northwest Water Power. 2019, 5. Available online: http:/ / en.cnki.com.cn/ Article_en/CJFDTotal-SBXX201905002.htm (accessed on 1 July 2021). 